\title{
Exploring the predictors of depression among Saudi adolescents
}

\author{
Time for urgent firm actions
}

Nada A. AlYousefi, SBFM, ABFM, Mohammed O. AlRukban, SBFM, ABFM, Abdullah M. AlMana, MBBS,

Talal H. AlTukhaim, MBBS, Basel A. AlMeflh, MBBS, Yazeed O. AlMutairi, MBBS, Omar S. AlMogheer, MBBS.

\begin{abstract}
الأهداف : تقدير انتشار الاكتئاب لدى الطلاب المراهقين وشدته والتعرف على

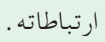

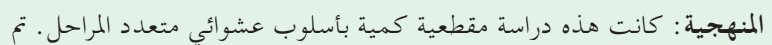

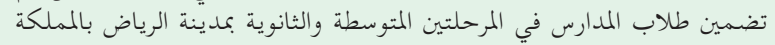

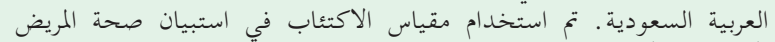
(PHQ-9)

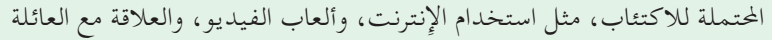

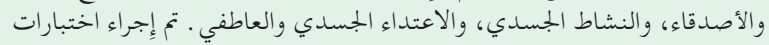

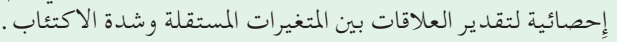

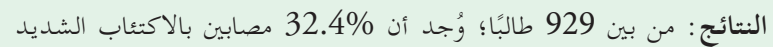

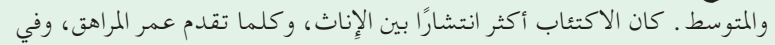

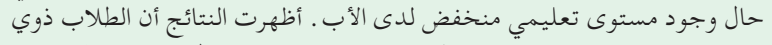

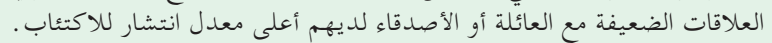

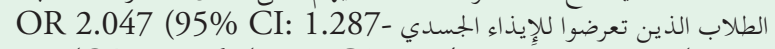

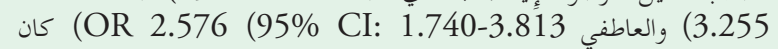

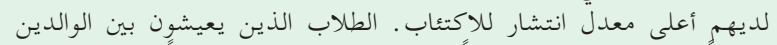

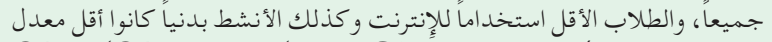

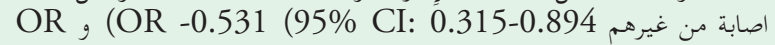
. (-0.668 (95\% CI: 0.468-0.953

الخلاصة : الانتشار الكبير للاكتئاب بين المراهقين السعوديين مثير للقلق . يجب

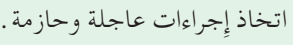

Objectives: To estimate the prevalence of depression among Saudi adolescents and identify its correlates.

Methods: This was a cross-sectional study using a multistage random technique that included students at the intermediate and secondary levels in Riyadh, Saudi Arabia. Patient Health Questionnaire (PHQ-9) was used as a tool, in addition to a survey of the potential risk factors. Binary logistic regression was conducted.

Results: Out of 960 students, $32.4 \%$ were found to have moderate to severe depression. The age group of 16-19 years was more at risk. Female gender and low father's education level were significant predictors of depression. Less internet use and more physical activity are considered a protective factor against depression, OR -0.531 (95\% CI: $0.315-0.894)$ and OR -0.668 (95\% CI: $0.468-0.953)$, respectively. Whereas the physical abuse, OR 2.047 (95\% CI: 1.287-3.255) and emotional abuse, OR 2.576 (95\% CI: 1.740-3.813) considered risk factors for depression.

Conclusion: The prevalence of depression among Saudi adolescents is worrisome. Urgent and firm actions should be taken in response to the increasing prevalence of depression worldwide.

Keywords: depression, adolescents, Saudi Arabia

Saudi Med J 2021; Vol. 42 (6): 673-681 doi: 10.15537/smj.2021.42.6.20200790

From the Department of Family and Community Medicine (AlYousefi, AlRukban), College of Medicine (AlMana, AlTukhaim, AlMeflh, AlMutairi, AlMogheer), King Sand University; and from the King Saud University Medical City (AlYousefi, AlRukban), King Saud University, Riyadh, Kingdom of Saudi Arabia.

Received 9th December 2020. Accepted 9th April 2021.

Address correspondence and reprint request to: Dr. Nada A. Alyousefi, Associate Professor, Department of Family and Community Medicine, College of Medicine, King Saud University, Riyadh, Kingdom of Saudi Arabia.E-mail: nalyousefi@ksu.edu.sa

ORCID ID: http://orcid.org/0000-0002-9142-425X

$\mathrm{D}$ epression is a common mental disorder that can occur for different reasons. However, several factors increase the vulnerability to depression, such as genetics, familial environment, personal characteristics, and severe stress. Some researchers found an association between depression and several other factors, such as being female, family history of depression, low income, negative cognitive style, and negative life events. ${ }^{1,2}$ Depression can be diagnosed according to the American Psychiatric Association's Diagnostic and 
Statistical Manual of Mental Disorders, fifth edition, (DSM-V) criteria. An individual must experience 5 or more symptoms during the same 2-week period, and the symptoms must not be a result of substance abuse or another medical condition. At least one of the symptoms should be either 1) depressed mood or 2) loss of interest or pleasure. ${ }^{3,4}$ Depending on the number and severity of symptoms, an episode of depression can be categorized as mild, moderate, or severe. ${ }^{2,5}$ Adolescents aged 10-24 years comprise nearly 25\% (1.8 billion) of the world's total population, which is 7.3 billion population. ${ }^{6}$ Of the 1.8 billion, almost 9 out of 10 live in less developed countries. ${ }^{6}$ In the Arab region, most of the population is below 25 years. ${ }^{7}$ Likewise, in Saudi Arabia (SA), 20\% of the 28 million people are between 10 and 19 years. ${ }^{8}$ There has been an $18 \%$ increase in the prevalence of depression between 2005 and $2015 .^{9}$ This reflects the global population's overall growth and a proportionate increase in the age groups where depression is more prevalent. The total number of people living with depression worldwide is 322 million. The prevalence of depression in adolescents falls within the wide range from $14.2 \%$ to $42.9 \%$ reported by previous studies conducted in Saudi Arabia. ${ }^{10-13}$ The dilemma in adolescent depression is that it is not easy to detect because of its nonspecific symptoms and atypical presentation. ${ }^{14}$ Suicide, which is a major consequence in depressed adolescents, is the second leading cause of death between 15 and 29 years of age globally. ${ }^{1,9,15}$ It is documented to be the second leading cause of death in the 10- to 19-year-old age group in the United Kingdom. ${ }^{14}$ It was also reported as the second leading cause of death in the 15- to 19-year-old age group by the Centers for Disease Control and Prevention in its report of the Underlying Cause of Death 1999-2019 released in 2020. ${ }^{16}$ More than half of adolescent suicide victims were reported to have a depressive disorder at the time of death; ${ }^{17}$ hence, these reports reflect the risk of an untreated severe depressive episode, leading to suicidal death, especially in adolescents. Moreover, several studies have stated that depression in adolescents tends to continue throughout life. ${ }^{9,18}$

Although multiple studies in Saudi Arabia have confirmed an increase over the past few years in students

Disclosure. Authors have no conflict of interests, and the work was not supported or funded by any drug company. suffering from depression. ${ }^{10-13}$ More studies, including a more representative sample, are essential to identify depression risk factors in adolescents. This study aimed to estimate the prevalence of depression among Saudi adolescents, its severity, and identify its correlates. The findings could pave the way for developing depression prevention and treatment services for at-risk students.

Methods. A quantitative observational crosssectional study targeting students at the intermediate and secondary levels in Riyadh was conducted between January 2019 and April 2019.

Study participants were included based on the following criteria: Saudi male and female adolescent students aged between 12-19 years. Students with any previous diagnosis of the mental condition were excluded.

As the sample will be taken from intermediate and secondary schools, namely, adolescents from Grade 7 through Grade 12 were included, a cut-off of 12-19 years was used. This cut-off (12-19) was mentioned in the literature as a definition of adolescence by Erik Erikson ${ }^{19}$ and Colarusso. ${ }^{20}$ In the recent literature, this cut-off was used widely in the researches concerning adolescents, ${ }^{21-23}$ including Asian countries ${ }^{24}$ and depression-related researches. ${ }^{25-27}$ A study cohort comprising 929 adolescents was required based on the following equation: Given that $\mathrm{z}=1.96, p=32 \%$, $\mathrm{d}= \pm 3 \% \mathrm{n}=[1.962 \times 0.32 \times(1-0.32)] / 0.032, \mathrm{n}=929$ Where $\mathrm{z}$ is constant, $\mathrm{p}$ is the estimated prevalence of depression in previous studies, $\mathrm{d}$ is the margin of error, and $\mathrm{n}$ is the sample size.

A multistage random technique was applied to achieve the geographical distribution of the sample population. Riyadh was divided into 5 sectors (north, south, east, west, and center). As most adolescents are enrolled in schools, a list of schools from each sector was obtained from the general administration of public education in Riyadh; 4 schools were selected from each sector randomly. The schools were stratified into 6 levels, from the first-year intermediate to third-year secondary level; from each level, a class was selected using a simple random technique. Ten students from each class were asked to participate; every other student in a row was asked to participate to equal the number of students sitting in the front rows with the back rows.

Upon revising the literature, the tools used for depression screening are the Center for Epidemiological Studies-Depression Scale ${ }^{28}$ ), the Beck Depression Inventory-II, ${ }^{29}$ and the Patient Health Questionnaire (PHQ-9), which consists of 9 items that focus on the 
Diagnostic and Statistical Manual (DSM-IV) criteria. ${ }^{30}$ Among these, the PHQ-9 was found to be a useful instrument for identifying and initiating the diagnosis of depression. The PHQ-9 had the highest positive predictive value, with a sensitivity of $73 \%$ and specificity of $94 \% .{ }^{31}$ A recently published study demonstrated that the Arabic version of the PHQ is a valid and reliable tool to screen for depression in a Saudi population. ${ }^{32}$

Data were collected by trained data collectors using a questionnaire composed of 3 parts: the first part was about sociodemographics such as age, gender, nationality, school grade, type of school, and parents' education and marital status.

The second part was the PHQ-9, which consisted of 9 items used to screen depression. Each item was rated on a four-point scale ranging from 0 (not at all) to 3 (nearly every day) for a total score of 0 to $27 . .^{30}$ The total score obtained from the PHQ-9 was used to determine the presence and severity of depression and was categorized as 1-4, minimal; 5-9, mild; 10-14, moderate; 15-19, moderate to severe; and 20-27, severe depression. ${ }^{30}$ The specificity and sensitivity of the PHQ-9 were estimated based on multiple studies to be $89 \%$ and $81 \%$, respectively. ${ }^{30,33}$ The cutoff score for positive screening for depression is 10 points. ${ }^{30}$

The third part focused on the potential risk factors for depression, including daily Internet use, hours of playing video games, relationship with family and friends, physical activity, physical abuse, and emotional abuse. A pilot study was conducted in Riyadh's intermediate schools to assess the questionnaire's clarity and comprehensiveness. It appeared to be well understood by the students.

Ethical approval was obtained from the IRB Committee of King Saud University, College of Medicine, Riyadh, Saudi Arabia. The investigators obtained consent from the school administration and participants prior to data collection. The questionnaire's consent form included a clear explanation of the research, its objectives, and its impact. Participants' anonymity was assured by assigning each participant with a code number for analysis only.

Statistical analysis. Data were analyzed using IBM SPSS Statistics for Windows, version 25.0 (IBM Corp., Armonk, N.Y., USA). Frequencies and percentages are reported for categorical variables. Chi-square was applied to observe associations between categorical variables. A p-value of $<0.05$ was considered statistically significant. Bivariate analyses were conducted to discern any nonlinear relationships or interaction effects and examine each independent variable's associations and the dependent variable, namely, depressed or not depressed, as the cutoff score for positive screening for depression is $10 .^{30}$ Binary logistic regression, including those statistically significant variables, was conducted independently estimating the relationships between those variables and the depression.

Results. Table 1 shows the participants' sociodemographic data with correlation to the severity of depression. Of the 960 Saudi adolescents, 419 $(51.7 \%)$ were $16-19$ years old, and 464 (48.3\%) were $12-15$ years old. Four hundred ninety-three (51.4\%) participants were male and 467 (48.6\%) female. A total of $600(62.5 \%)$ participants were from private schools. Students whose parents lived together were $870(90.6 \%)$, those whose parents were divorced were $63(6.6 \%)$, and those who were orphans were 27 (2.8\%). Out of 960,649 (67.6\%) had mild depression, 194 (20.2\%) had moderate depression, 117 (12.2\%) had severe depression. Out of 960 participants, 817 $(85.1 \%)$ used the Internet for 3 hours and more. Only $34(3.5 \%)$ had a poor relationship with their family. Only $40(4.2 \%)$ had a poor relationship with their friends. Most students (64.4\%), not physically active. Seventeen percent of participants suffered from physical abuse. Approximately $26.9 \%$, suffered from emotional abuse. There is a significant association between age and depression severity $(p=0.002)$ as age increased. Compared to males, females had a significantly higher depression prevalence with a higher severity level $(p=0.000)$. Public school students had a higher depression prevalence than private school students $(p=0.004)$. A significant association was found between the father's education level and the prevalence of depression $(p=0.004)$. Whereas the mother's education level was not found to be a significant factor $(p=0.159)$. The parent marital status was appeared to be associated significantly with depression severity $(p=0.031)$. There is a relationship between depression and relationship status with family or friends. Students with poor relationships with family or friends had the highest prevalence of depression; in contrast, students with very good relationships with family or friends had the lowest prevalence of depression $(p=0.000)$. Although more internet usage is associated with depression severity $(p=0.000)$, no significant association was observed between the severity of depression and playing video games $(p=0.169)$. Students who physically active had a lower prevalence of depression $(p=0.000)$. Students who were physically or emotionally abused had a higher 
Worrisome prevalence in Saudi adolescents ... Alyousefi et al

Table 1 - Distribution of sociodemographic characteristics of study participants, exposure to depression risk factors, and its association with severity of depression among adolescent students in Riyadh ( $\mathrm{n}=960)$.

\begin{tabular}{|c|c|c|c|c|}
\hline \multirow[t]{2}{*}{ Variables } & \multicolumn{4}{|c|}{ Depression Status n (\%) } \\
\hline & $\begin{array}{c}\text { Mild } \\
\mathrm{n}=649(67.6)\end{array}$ & $\begin{array}{c}\text { Moderate } \\
\mathrm{n}=194(20.2)\end{array}$ & $\begin{array}{c}\text { Severe } \\
\mathrm{n}=117(12.2) \\
\end{array}$ & $P$-value \\
\hline \multicolumn{5}{|l|}{ Age } \\
\hline $12-15$ & $340(73.3)$ & $75(16.2)$ & $49(10.6)$ & \multirow[t]{2}{*}{$0.002^{*}$} \\
\hline $16-19$ & $309(62.3)$ & $119(24)$ & $68(13.7)$ & \\
\hline \multicolumn{5}{|l|}{ Gender } \\
\hline Male & $379(76.9)$ & $73(14.8)$ & $41(8.3)$ & \multirow[b]{2}{*}{$0.000^{*}$} \\
\hline Female & $270(57.8)$ & $121(25.9)$ & $76(16.3)$ & \\
\hline \multicolumn{5}{|l|}{ Grade } \\
\hline Intermediate school & $314(71.4)$ & $75(17.0)$ & $51(11.6)$ & \multirow{2}{*}{0.051} \\
\hline Secondary school & $335(64.4)$ & $119(22.9)$ & $66(12.7)$ & \\
\hline \multicolumn{5}{|l|}{ School type } \\
\hline Public & $216(60)$ & $97(26.9)$ & $47(13.1)$ & \multirow[t]{2}{*}{$0.004^{*}$} \\
\hline Private & $433(72.2)$ & $97(16.2)$ & $70(11.7)$ & \\
\hline \multicolumn{5}{|l|}{ Mother education level } \\
\hline Low & $191(64.1)$ & $67(22.5)$ & $40(13.4)$ & \multirow{3}{*}{0.186} \\
\hline High & $305(66.7)$ & $95(21.0)$ & $56(12.3)$ & \\
\hline Not known & $153(74.6)$ & $32(15.1)$ & $21(10.2)$ & \\
\hline \multicolumn{5}{|l|}{ Father education level } \\
\hline Low & $83(53.5)$ & $48(31.0)$ & $24(15.5)$ & \multirow{3}{*}{$0.004^{*}$} \\
\hline High & $431(70)$ & $110(17.9)$ & $75(12.2)$ & \\
\hline Not known & $135(71.4)$ & $36(19.0)$ & $18(9.5)$ & \\
\hline \multicolumn{5}{|l|}{ Parents Status } \\
\hline Married & $597(68.6)$ & $172(19.8)$ & $101(11.6)$ & \multirow{3}{*}{$0.031^{*}$} \\
\hline Divorce & $36(57.1)$ & $13(20.6)$ & $14(22.2)$ & \\
\hline One or both died & $16(59.3)$ & $9(33.3)$ & $2(7.4)$ & \\
\hline \multicolumn{5}{|l|}{ Internet Use } \\
\hline $0-2$ hours & $108(75.5)$ & $20(14.0)$ & $15(10.5)$ & \multirow{3}{*}{$0.000^{*}$} \\
\hline 3-4 hours & $197(75.2)$ & 47 (17.9) & $18(6.9)$ & \\
\hline$\geq 5$ hours & $344(62)$ & $127(22.9)$ & $84(15.1)$ & \\
\hline Video Games & & & & \\
\hline $0-2$ hours & $461(67.3)$ & $143(20.9)$ & $81(11.8)$ & \\
\hline $3-4$ hours & $111(73.5)$ & $26(17.2)$ & $14(9.3)$ & 0.169 \\
\hline$\geq 5$ hours & $77(62.1)$ & $25(20.2)$ & $22(17.7)$ & \\
\hline Relationship with fami & & & & \\
\hline Poor & $5(14.7)$ & $9(26.5)$ & $20(58.8)$ & $00 \Omega 0$ * \\
\hline Somewhat good & $78(36.8)$ & $76(35.8)$ & $58(27.4)$ & $0.000^{*}$ \\
\hline Very good & $566(79.3)$ & $109(15.3)$ & $39(5.5)$ & \\
\hline Relationship with frien & & & & \\
\hline Poor & $15(37.5)$ & $9(22.5)$ & $16(40.0)$ & \\
\hline Somewhat good & $109(53.7)$ & $53(26.1)$ & $41(20.2)$ & $0.000^{*}$ \\
\hline Very good & $525(73.2)$ & $132(18.4)$ & $60(8.4)$ & \\
\hline Physically Active & & & & \\
\hline Yes & $259(75.7)$ & $59(17.3)$ & $24(7.0)$ & \\
\hline No & $390(63.1)$ & $135(21.8)$ & $93(15.0)$ & $0.000^{*}$ \\
\hline Experienced physical vi & & & & \\
\hline a parent & & & & \\
\hline Yes & $70(42.9)$ & $44(27.0)$ & $49(30.1)$ & $0.000^{*}$ \\
\hline No & $579(72.6)$ & $150(18.8)$ & $68(8.5)$ & $0.000^{*}$ \\
\hline $\begin{array}{l}\text { Experienced emotional } \\
\text { by a parent }\end{array}$ & & & & \\
\hline Yes & $101(39.1)$ & $83(32.2)$ & $74(28.7)$ & \\
\hline No & $548(78.1)$ & $111(15.8)$ & $43(6.1)$ & $0.000^{*}$ \\
\hline $\begin{array}{l}\text { The difficulty level in d } \\
\text { tasks or get along with }\end{array}$ & & & & \\
\hline Not difficult at all & $401(88.3)$ & $40(8.8)$ & $13(2.9)$ & \\
\hline Somewhat difficult & $234(56.5)$ & $122(29.5)$ & $58(14.0)$ & \\
\hline Very difficult & $12(17.1)$ & $29(41.4)$ & $29(41.4)$ & $0.000^{*}$ \\
\hline Extremely difficult & $2(9.1)$ & $3(13.6)$ & $17(77.3)$ & \\
\hline
\end{tabular}


prevalence of depression $(p<0.000)$. The severity of depression appeared to have a relationship with the difficulty of performing tasks $(p=0.000)$, as shown in Table 1. People with severe depression reported having more difficulties performing daily activities than those with lower levels of depression, indicating the disease's burden.
Table 2 shows the binary logistic regression results of the possible predictors of depression. Although the age group of 12-15 seems to be less likely to have depression OR: -0.775 (CI 95\%: 550-1.092), the association was not significant. Also, the type of school was not found to be a predictor. Gender is a significant predictor. Male students will be less likely to have depression, OR: - 0.539

Table 2 - Binary logistic regression model results of possible predictors of depression among adolescent students in Riyadh.

\begin{tabular}{|c|c|c|c|c|c|c|c|}
\hline Variables & B & Std. Error & Wald & $\mathrm{df}$ & Sig. & OR & 95\% Confidence Interval \\
\hline \multicolumn{8}{|l|}{ Age } \\
\hline $12-15$ & -0.255 & 0.175 & 2.123 & 1 & 0.145 & 0.775 & $0.550-1.092$ \\
\hline $16-19$ & REF & & & & & & \\
\hline \multicolumn{8}{|l|}{ Gender } \\
\hline Male & -0.618 & 0.197 & 9.807 & 1 & 0.002 & 0.539 & $0.366-0.794$ \\
\hline Female & REF & & & & & & \\
\hline \multicolumn{8}{|l|}{ School type } \\
\hline Public school & 0.130 & 0.199 & 0.426 & 1 & 0.514 & 1.139 & $0.771-1.681$ \\
\hline Private school & REF & & & & & & \\
\hline \multicolumn{8}{|l|}{ Father education } \\
\hline Low & 0.670 & 0.220 & 9.316 & 1 & 0.002 & 1.955 & $1.271-3.006$ \\
\hline High & REF & & & & & & \\
\hline \multicolumn{8}{|l|}{ Parents status } \\
\hline Married & -0.551 & 0.456 & 1.460 & 1 & 0.227 & 0.576 & $0.236-1.409$ \\
\hline Divorced & -0.284 & 0.546 & 0.270 & 1 & 0.603 & 0.753 & $0.258-2.197$ \\
\hline One or both died & REF & & & & & & \\
\hline \multicolumn{8}{|l|}{ Internet Use } \\
\hline $0-2$ hours & -0.633 & 0.266 & 5.661 & 1 & 0.017 & 0.531 & $0.315-0.894$ \\
\hline $3-4$ hours & -0.432 & 0.196 & 4.871 & 1 & 0.027 & 0.649 & $0.442-0.953$ \\
\hline$\geq 5$ hours & REF & & & & & & \\
\hline \multicolumn{8}{|l|}{ Relation with family } \\
\hline Poor & 2.215 & 0.534 & 17.209 & 1 & 0.000 & 9.163 & $3.217-26.096$ \\
\hline Good & 1.244 & 0.196 & 40.431 & 1 & 0.000 & 3.469 & $2.364-5.091$ \\
\hline Very good & REF & & & & & & \\
\hline \multicolumn{8}{|l|}{ Relation with friends } \\
\hline Poor & 1.291 & 0.400 & 10.406 & 1 & 0.001 & 3.637 & $1.660-7.969$ \\
\hline Good & 0.423 & 0.199 & 4.501 & 1 & 0.034 & 1.527 & $1.033-2.257$ \\
\hline Very good & REF & & & & & & \\
\hline \multicolumn{8}{|l|}{ Physical activity } \\
\hline Yes & -0.403 & 0.181 & 4.944 & 1 & 0.026 & 0.668 & $0.468-0.953$ \\
\hline No & REF & & & & & & \\
\hline \multicolumn{8}{|l|}{ Physical abuse } \\
\hline Yes & 0.716 & 0.237 & 9.152 & 1 & 0.002 & 2.047 & $1.287-3.255$ \\
\hline No & REF & & & & & & \\
\hline \multicolumn{8}{|l|}{ Emotional abuse } \\
\hline Yes & 0.946 & 0.200 & 22.337 & 1 & 0.000 & 2.576 & $1.740-3.813$ \\
\hline No & REF & & & & & & \\
\hline
\end{tabular}


(CI 95\%: 0.366-0.794) compared to female students. The father's education level is a predictor of having depression, namely, if the father has a low educational level, the student will have 1.955 times (CI 95\%: 1.271-3.006) more chance to have depression. A student who lived with both parents will be less likely to develop depression, OR: 0.576 (CI 95\%: 0.236-1.409). Although the initial correlation was positive for parents' status, it was not significant in the logistic regression. Less internet use appeared to have a protective effect from depression, OR: 0.531 (CI 95\%: 0.315-0.894). A poor relationship with family is a strong predictor of depression with OR: 9.163 (CI 95\%: 3.217-26.1). Also, poor relations with friends will be associated with depression, OR: 3.637 (CI 95\%: 1.660-7.969). Staying physically active is considered a protective factor against depression, OR: 0.668 (CI 95\%: 0.468-0.953). Whereas the physical abuse, OR: 2.047 (CI 95\%: 1.287-3.255) and emotional abuse, OR: 2.576 (CI 95\%: 1.74-3.81) considered risk factors for depression.

Discussion. A depression diagnosis is relatively common in children and adolescents and is strongly associated with morbidity and suicidal tendency; ${ }^{34}$ thus, it is important to have further information about it. A survey conducted in the United States targeting adolescents showed that the 1-year prevalence of major depression was $8 \% .{ }^{15}$ This study's outcome showed a prevalence of $32.4 \%$, which lies within the range reported previously. A survey conducted in Abha and Aseer regions on adolescent schoolboys showed that $38.2 \%$ had depression. ${ }^{12}$ A study conducted among high school students in the Qassim region showed that $34 \%$ were mildly depressed, $24.6 \%$ were moderately depressed, and $15.4 \%$ were moderate to severely depressed. ${ }^{35}$

Several studies have shown an increase in the level of depression with increasing age into adolescence. ${ }^{36,37}$ In India, Jaisoorya et $\mathrm{al}^{38}$ also reported increased depression with older adolescents. The Jeeluna national study found that feeling deeply sad or hopeless and worried was significantly more prevalent among females and older adolescents $(p<0.0001),{ }^{39}$ which is consistent with the findings of this study, where depression among female adolescents was more prevalent than those among males.

As the severity of depression was showed significant gender differences in the adolescent population. Lutz Wartberg et $\mathrm{al}^{37}$ study showed that girls are 2.36 times more likely to be depressed than boys. The Qassim region study also showed a significant relationship between depression and gender. ${ }^{35}$ Females tend to be the predominant gender in the prevalence of depression. A study in 2015 showed that $42.9 \%$ of secondary school girls in Taif city have significant depression, ${ }^{40}$ which was the highest prevalence of depression among the studies conducted in Saudi Arabia concerning this age group.

Saudi Arabia provides free education to its citizens through public schools, which may be a good choice for lower-income families. The school type can give us an indication of the financial well-being of the student's family. This study found that students who went to public schools have a higher prevalence of depression, which could be due to the many challenges public school students face, such as poor health care, poor student counseling, inappropriate educational environment, and many other factors requiring further investigation.

Depression among adolescents is significantly affected by parents' level of education. Students who had less educated fathers had a higher prevalence of depression than their counterparts; this could result from a lack of knowledge of the disease and inappropriate interventions, which might worsen their condition.

Jaisoorya et $\mathrm{a}^{38}$ reported that the student who is not living with both parents was significantly associated with psychological distress. The depression resulted from a lack of support at home and increased responsibilities of the adolescent or the emotional burden forced upon the student to not live like his peers. Two percent of the study population was orphaned; only 2 participants had severe depression according to the PHQ-9 scale. The culture in Saudi Arabia may have a role in such results as Saudis tend to have large families that can provide emotional and financial support to the less fortunate kids, and dedicated specialized governmental institutions offer care and aid to the people in need, which may have contributed to the lower prevalence of depression among orphaned adolescent students.

Poor relationships with family and friends negatively affect students' lives. An increase in the level of depression is noted in those who have poor relationships with their friends and families, as shown by this study. A study conducted in Saudi Arabia achieved similar results with this study, where a strong association between depression and relationships with peers and family was established. ${ }^{11}$ The Jeeluna national survey found that poor relationships with parents, negative body image, and chronic illness were significantly associated with feeling sad or hopeless. ${ }^{39}$ Some researchers support the argument that Internet addiction can be associated with depression, ${ }^{41}$ which aligns with this study results. The results show that with increased daily use of the Internet, there is an increase in the prevalence of depression. In 
comparison, other researchers have stated that Internet abusers share common behavioral mechanisms with depression, ${ }^{42}$ namely, Internet abusers were associated with a depressive state but not a depressive trait. Thus, further studies are required to test the relationship between Internet addiction and depression.

The current study results showed that increased daily physical activity was inversely proportional to a higher prevalence of depression; physical activity, as stated by another study, has beneficial effects on depression symptoms comparable to antidepressant treatments. ${ }^{43}$

A high percentage of Saudi adolescent students reported suffering from domestic physical (17\%)and emotional abuse (26.9\%). Exposure to either of these 2 factors was significantly associated with a higher prevalence of depression, indicating that the depression could be attributed to these 2 factors more than other factors listed in this study.

Domestic abuse may have a direct role in depression. Simultaneously, its indirect contribution is the decrease in parents' trust that may put the student in an isolated position with helplessness and lack of support or place them in a long-term state of self-doubt. This highlights the extreme importance of preventing these 3 factors: encouraging parental counseling after marriage, providing hotlines to ensure appropriate early intervention, or increasing the student's counselor's role in schools.

Approximately one-third of the adolescent student population was screened positive for depression, which shows the importance of addressing this issue. As recommended by the United States Preventive Services Task Force, annual screening should be carried out in schools ${ }^{31}$ and improve schools' emotional and environmental states.

The study's strength was that it was carried out with a valid tool to screen for depression using a multistage random technique to achieve the sample population's geographical distribution. The study limitation was that the results could not be generalized to all Saudi adolescents. We need to conduct a national multicity study to obtain a precise view of the prevalence. Waiting for the Saudi National Mental Health Survey's detailed results, a survey of a nationally representative sample of Saudi citizens aged 15-65 years of common mental disorders, which was conducted between 2011 and 2016, can lighten the road for decision-making and firm actions. ${ }^{44}$ In response to the increasing prevalence of depression in adolescents, the ministry of education approved the exploratory examination, including screening for depression just before the COVID-19 lockdown and distant learning. The plan was aiming for early detection of depression, the first screening to be for students of the first intermediate grade and first-grade secondary school by using the Quick (PHQ-9 Depression Assessment Questionnaire). The COVID-19 pandemic has increased the current prevalence of depression among youth due to restrictions and prolonged lockdowns. A multi-Arab country study of adolescents found a $57 \%$ prevalence of depression with no significant differences between countries. ${ }^{15}$ Thus, this crisis may increase the current prevalence of depression which requires public health institutes special attention. A systematic review and meta-analysis of the COVID-19 pandemic showed the prevalence of depression in 14 studies with a sample size of 44,531 people $(33.7 \%) .{ }^{45}$ Once the on-campus education is resumed, screening, intervention, and support should take place.

In conclusion, the significant prevalence of depression among Saudi adolescents is worrisome. Educational institutions should take urgent and firm actions to collaborate with health-care professionals and facilities to reduce the prevalence and control of associated factors, especially after the COVID-19 pandemic. The results obtained from this study would contribute greatly to establishing a sufficient and reliable database about depression, increasing awareness about depression and its associated factors, and promoting adolescents' mental health in Saudi Arabia. We recommend annual screening for depression to detect the prevalence of depression and to assess the effectiveness of the promotional school programs for mental health.

Acknowledgment. We would like to thank Amirah Alzahrani, Dareen Alassiri, Ebtisam Almutairi, Haifa Alessa, and Majd Albarrak for their contribution in the data collection process.

\section{References}

1. Schwartz B, Kaminer D, Hardy A, Nöthling J, Seedat S. Gender differences in the violence exposure types that predict PTSD and depression in adolescents. J Interpers Violence 2019; 0886260519849691.

2. National Collaborating Centre for Mental Health (UK). Depression: The Treatment and Management of Depression in Adults (Updated Edition). Leicester (UK): British Psychological Society; 2010.

3. Tolentino JC, Schmidt SL. DSM-5 criteria and depression severity: implications for clinical practice. Front Psychiatry 2018; 9: 450.

4. Cicchetti D, Toth SL. The development of depression in children and adolescents. Am Psychol 1998; 53: 221.

5. Kessler RC, Bromet EJ. The epidemiology of depression across cultures. Annu Rev Public Health 2013; 34: 119-138. 
6. Gupta M Das, Engelman R, Levy J, Luchsinger G, Merrick T, Rosen JE, et al. State of World Population 2014 The Power of 1,8 billion Adolescents, Youth and the Transformation of the Future. UNFPA. New York (NY): United Nations Population Fund; 2014.

7. United Nations Economic and Social Commission for Western Asia (ESCWA). Regional Overview: Youth in the Arab Region. Beirut (LB): United Nations Economic and Social Commission for Western Asia (ESCWA); 2013.

8. The United States Census Bureau. International Data Base Population Estimates and Projections Methodology. Maryland, (USA): The United States Census Bureau; 2013.

9. World Health Organization. Depression and other common mental disorders: global health estimates. Geneva (SW): World Health Organization; 2017.

10. AlBuhairan FS, Tamim H, Al Dubayee M, AlDhukair S, Al Shehri S, Tamimi W, et al. Time for an adolescent health surveillance system in Saudi Arabia: findings from "Jeeluna." J Adolesc Heal 2015; 57: 263-269.

11. Raheel H. Depression and associated factors among adolescent females in Riyadh, Kingdom of Saudi Arabia, a cross-sectional study. Int J Prev Med 2015; 6: 90.

12. Al-Gelban KS. Depression, anxiety and stress among Saudi adolescent school boys. J R Soc Promot Health 2007; 127: 33-37.

13. Asal AR, Abdel-Fattah MM. Prevalence, symptomatology, and risk factors for depression among high school students in Saudi Arabia. Neurosciences 2007; 12: 8-16.

14. Windfuhr K, While D, Hunt I, Turnbull P, Lowe R, Burns J, et al. Suicide in juveniles and adolescents in the United Kingdom. J Child Psychol Psychiatry 2008; 49: 1155-1165.

15. Perou R, Bitsko RH, Blumberg SJ, Pastor P, Ghandour RM, Gfroerer JC, et al. Mental health surveillance among childrenUnited States, 2005-2011. MMWR Suppl 2013; 62: 1-35.

16. Centers for Disease Control and Prevention National Center for Health Statistics. Underlying cause of death 1999-2019 on CDC WONDER Online Database. USA: The National Center for Health Statistics; 2020.

17. Hawton K, van Heeringen K. Suicide. Lancet (London, England) 2009; 373: 1372-1381.

18. Kalinowska S, Nitsch K, Duda P, Trześniowska-Drukała B, Samochowiec J. [Depression in children and adolescentssymptoms, etiology, therapy]. Ann Acad Med Stetin 2013; 59: 32-36. Polish

19. Harder AF. The developmental stages of Erik Erikson. Leaning Place Online.com; 2002. [cited 2002]. Available from: https:// pact.tarleton.edu/tcert/content/Documents/EriksonDev.pdf

20. Colarusso CA. Child and adult development: A psychoanalytic introduction for clinicians. Berlin (GR): Springer Science \& Business Media; 1992.

21. Ruiz LD, Zuelch ML, Dimitratos SM, Scherr RE. Adolescent obesity: Diet quality, psychosocial health, and cardiometabolic risk factors. Nutrients 2019; 12: 43.

22. Paes-Silva RP, Gadelha PCFP, Lemos M da CC de, Castro CMMB de, Arruda IKG de, Diniz A da S. Adiposity, inflammation and fat-soluble vitamins in adolescents. J Pediatr (Rio J) 2019; 95: 575-583.

23. Gray KM, Rubinstein ML, Prochaska JJ, DuBrava SJ, Holstein AR, Samuels L, et al. High-dose and low-dose varenicline for smoking cessation in adolescents: a randomised, placebocontrolled trial. Lancet Child Adolesc Heal 2020; 4: 837-845.
24. Mazidi M, Banach M, Kengne AP, Group L and BPMC. Prevalence of childhood and adolescent overweight and obesity in Asian countries: a systematic review and meta-analysis. Arch Med Sci AMS 2018; 14: 1185.

25. Mak HW, Fosco GM, Lanza ST. Dynamic Associations of Parent-Adolescent Closeness and Friend Support With Adolescent Depressive Symptoms Across Ages 12-19. J Res Adolesc 2020; Nov: doi: 10.1111/jora.12597.

26. Skovlund CW, Kessing LV, Mørch LS, Lidegaard Ø. Increase in depression diagnoses and prescribed antidepressants among young girls. A national cohort study 2000-2013. Nord J Psychiatry 2017; 71: 378-385.

27. Wiens K, Williams JVA, Lavorato DH, Duffy A, Pringsheim TM, Sajobi TT, et al. Is the prevalence of major depression increasing in the Canadian adolescent population? Assessing trends from 2000 to 2014. J Affect Disord [Internet] 2017; 210: 22-26.

28. Radloff LS. The CES-D scale: A self-report depression scale for research in the general population. Appl Psychol Meas 1977; 1: 385-401.

29. Beck AT, Steer RA, Carbin MG. Psychometric properties of the Beck Depression Inventory: Twenty-five years of evaluation. Clin Psychol Rev 1988; 8: 77-100.

30. Kroenke K, Spitzer RL, Williams JBW. The PHQ-9: validity of a brief depression severity measure. J Gen Intern Med 2001; 16: 606-613.

31. Siu AL, Bibbins-Domingo K, Grossman DC, Baumann LC, Davidson KW, Ebell M, et al. Screening for depression in adults: US Preventive Services Task Force recommendation statement. JAMA 2016; 315: 380-387.

32. AlHadi AN, AlAteeq DA, Al-Sharif E, Bawazeer HM, Alanazi $\mathrm{H}$, AlShomrani AT, et al. An arabic translation, reliability, and validation of Patient Health Questionnaire in a Saudi sample. Ann Gen Psychiatry 2017; 16: 32.

33. Arroll B, Goodyear-Smith F, Crengle S, Gunn J, Kerse N, Fishman T, et al. Validation of PHQ-2 and PHQ-9 to screen for major depression in the primary care population. Ann Fam Med 2010; 8: 348-353.

34. DeFilippis M, Wagner KD. Management of treatment-resistant depression in children and adolescents. Pediatr Drugs 2014; 16 : 353-361.

35. Alharbi R, Alsuhaibani K, Almarshad A, Alyahya A. Depression and anxiety among high school student at Qassim Region. $J$ Fam Med Prim Care 2019; 8: 504-510.

36. Green H, McGinnity Á, Meltzer H, Ford T, Goodman R. Mental health of children and young people in Great Britain, 2004. London (UK): Palgrave Macmillan Basingstoke; 2005.

37. Wartberg L, Kriston L, Thomasius R. Depressive symptoms in adolescents: prevalence and associated psychosocial features in a representative sample. Dtsch Arztebl Int 2018; 115: 549.

38. Jaisoorya TS, Desai G, Beena K V, Beena M, Ellangovan K, Thennarasu K. Prevalence and correlates of psychological distress in adolescent students from India. East Asian Archives of Psychiatry 2017; 27: 56.

39. Abou Abbas O, AlBuhairan F. Predictors of adolescents' mental health problems in Saudi Arabia: findings from the Jeeluna $\left({ }^{\circledR}\right)$ national study. Child Adolesc Psychiatry Ment Health 2017; 11: 52. 
40. Desouky Del-S, Abdellatif Ibrahem R, Salah Omar M. Prevalence and comorbidity of depression, anxiety and obsessive compulsive disorders among Saudi secondary school girls, Taif Area, KSA. Arch Iran Med 2015; 18: 234-238.

41. Ahmadi J, Amiri A, Ghanizadeh A, Khademalhosseini M, Khademalhosseini Z, Gholami Z, et al. Prevalence of addiction to the internet, computer games, DVD, and video and its relationship to anxiety and depression in a sample of Iranian high school students. Iran J psychiatry Behav Sci 2014; 8: 75.

42. Huang ACW, Chen H, Wang Y, Wang L. Internet abusers associate with a depressive state but not a depressive trait.
Psychiatry Clin Neurosci 2014; 68: 197-205.

43. Dinas PC, Koutedakis Y, Flouris AD. Effects of exercise and physical activity on depression. Ir J Med Sci 2011; 180: 319-325.

44. Al-Subaie AS, Al-Habeeb A, Altwaijri YA. Overview of the Saudi National Mental Health Survey. Int J Methods Psychiatr Res 2020; 29: e1835.

45. Al Omari O, Al Sabei S, Al Rawajfah O, Abu Sharour L, Aljohani $\mathrm{K}$, Alomari K, et al. Prevalence and predictors of depression, anxiety, and stress among youth at the time of COVID-19: An online cross-sectional multicountry study. Depress Res Treat 2020; 2020: 8887727. 